\title{
Buscant materials adients per insonoritzar un local per fer-hi música
}

\author{
Miquel Expósito Pérez i Irene Miquel Plana \\ IES Numància, Santa Coloma de Gramenet \\ imiquel2@xtec.cat
}

Es presenta un treball de recerca en el qual s'han estudiat diferents materials de construcció per tal d'analitzar quin és el que millor atenua el so. El treball experimental s'ha basat en la construcció d'un conjunt de capses, folrades amb diferents materials que reprodueixen un local on s'assaja amb un instrument musical, i en la mesura del nivell d'intensitat sonora emès per una font sonora tant a l'interior com a l'exterior de les capses.

Paraules clau: absorció sonora, condicionament acústic, insonorització, reflexió, treball de recerca

\section{Introducció}

Un dels objectius del treball de recerca del batxillerat és el d'aprofundir en algun dels continguts que per manca de temps no s'inclouen dins del currículum d'aquesta etapa educativa. Un d'aquests continguts, és l'acústica, la branca de la física que estudia les propietats del so.

En aquest treball concret l'alumne pretén obtenir un resultat pràctic ja que, a més dels estudis postobligatoris, també segueix estudis musicals i, per tant, ha de dedicar moltes hores a assajar amb el seu instrument. Donat que part de les hores que destina a assajar ho fa a la seva llar, es va mostrar interessat en estudiar quin material es pot utilitzar per tal d'insonoritzar i condicionar acústicament la seva habitació, fer-la el més adient possible per a la pràctica d'un instrument des de tres vessants: impedint l'entrada dels sons procedents de l'exterior, evitant que el so de l'instrument arribi als veïns i minimitzant el nombre de reflexions de forma que el músic percebi amb la màxima claredat i nitidesa la música generada.

Amb aquesta finalitat s'ha portat a terme el següent treball de recerca amb el que s'ha aprofundit en el coneixement de l'acústica i en el que s'ha portat a terme una part experimental encaminada a trobar una solució al problema plantejat.

\section{Requisits per insonoritzar un espai i condicionar-lo acústicament}

Una de les branques de l'acústica és l'anomenada acústica arquitectònica. Aquesta disciplina científica investiga quina és la millor forma de condicionar acústicament un local. És a dir, estudia quins són els millors materials, les millors estructures constructives, la millor disposició del mobiliari dins d'un local, etc. per tal que els sons que es produeixin en el seu interior es puguin escoltar sense cap tipus de distorsió.

Com resulta obvi, en la construcció d'auditoris, teatres, cinemes, o bé qualsevol altre recinte on es reprodueixen sons (ja siguin musicals o bé la veu mateixa) s'ha de tenir molt en compte el condicionament acústic per tal que l'espectador i els propis músics puguin percebre el so de forma clara i nítida.

En aquest treball ens hem centrat en quin és el millor material per condicionar acústicament un local i per tant hem analitzat tres de les seves propietats: la seva capacitat aillant, la seva capacitat absorbent i la seva capacitat reflectora.

Diem que un material és aïllant quan impedeix que el so penetri dins d'un espai o bé que en surti, és a dir, quan és capaç d'atenuar el so transmès a través seu. 
Per tal de calcular la capacitat aïllant d'un material simplement s'ha de mesurar la diferència entre el nivell d'intensitat sonora que incideix sobre el material i el que es transmet. En aquest treball ho farem comparant els decibels registrats a una certa distància d'una font sonora quan aquesta es troba a l'aire lliure i quan aquesta es troba a l'interior d'una capsa folrada amb el material objecte d'estudi.

Un material caracteritzat com a aillant ho pot ser per dos motius: o bé perquè és absorbent acústic 0 bé perquè és reflector acústic.

Un material reflector és aquell capaç de retornar bona part del so al mitjà del qual procedeix. Donat que el so és una ona mecànica, experimenta el fenomen de la reflexió i una part de l'energia acústica retorna al medi incident després d'haver xocat amb el material reflector, tal com es mostra a la fig. 1.
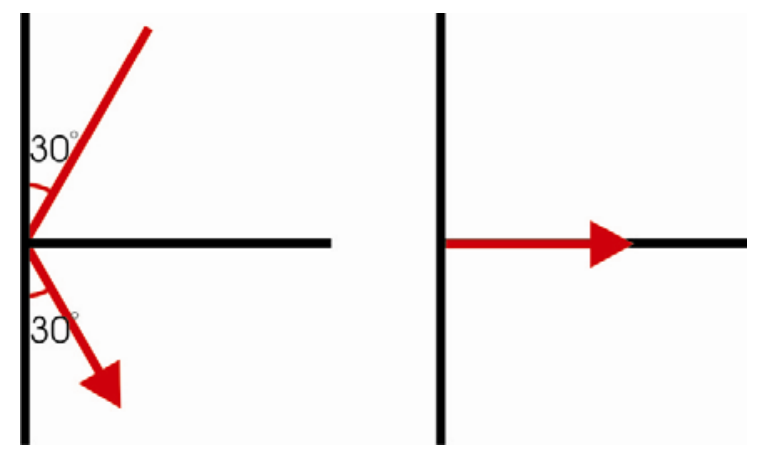

Figura 1. Reflexió sonora amb un angle d'incidència de $30^{\circ} \mathrm{i}$ amb una incidència perpendicular.

Els materials absorbents, en canvi, són capaços d'absorbir part de l'energia acústica transformant-la en altres tipus d'energia.

Per tal de diferenciar entre materials reflectors i absorbents de forma experimental s'ha comparat el nivell d'intensitat sonora emès per una font sonora situada primer a l'aire lliure i després a l'interior d'una capsa folrada amb el material objecte d'estudi. Si el nivell d'intensitat sonora enregistrat a l'interior de la capsa és superior a l'enregistrat a l'aire lliure, podem interpretar que el material és reflector acústic; en canvi si és inferior interpretem que el material és absorbent acústic.

\section{Plantejament de l'experiència}

Per a determinar com es comporten enfront del so sis materials diferents s'han construït sis capses de la mateixa mida (31 x $22 \times 8 \mathrm{~cm}$ corresponents a la mida d'una capsa de folis), i cada una s'ha folrat amb un material diferent: porexpan, fusta aglomerada, morter, llana de roca, xapa metàllica i rajola esmaltada. Cada capsa simula una habitació folrada d'aquest material. La construcció de les capses i de les tapes corresponents s'ha realitzat utilitzant els materials i les eines apropiades i assegurant en tot moment que les dimensions de les capses siguin les mateixes i, per tant, les mesures siguin comparables.

A cadascuna de les capses se li ha fet un forat de 13 mil.límetres de diàmetre amb un trepant en una de les seves cares, per tal de poder introduir el micròfon del sonòmetre per fer la mesura del nivell d'intensitat sonora.

Un cop construïdes les capses s'ha utilitzat un sonòmetre per realitzar dos tipus de mesures.

Les primeres, encaminades a determinar quin dels materials és millor aïllant, consisteixen en introduir a l'interior de les capses una font sonora de $440 \mathrm{~Hz}$ i mesurar el nivell d'intensitat sonora a 40 $\mathrm{cm}$ de la font sonora (fig. 2).

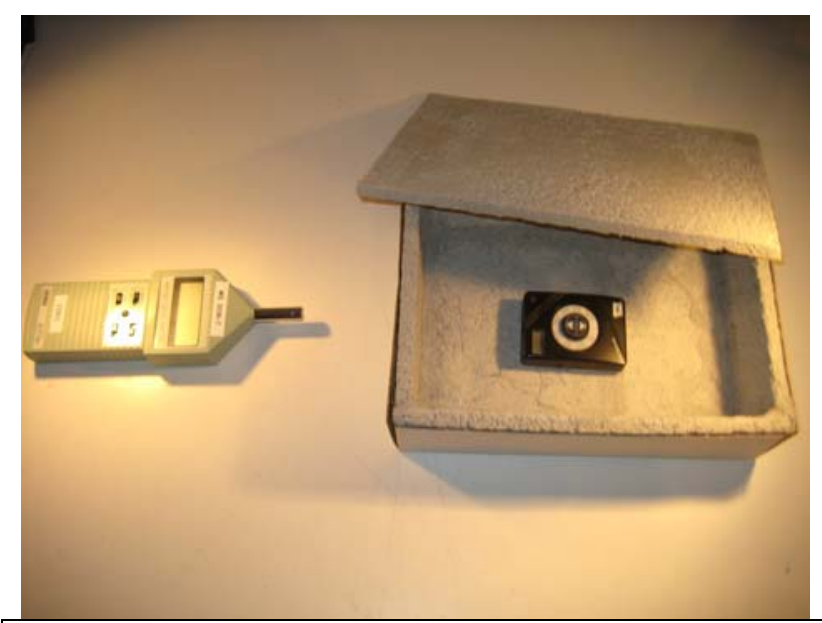

Figura 2. Font sonora a l'interior i sonòmetre a l'exterior de la capsa per tal de mesurar la capacitat aillant del material.

La segona tanda de mesures, encaminades a determinar quins materials són reflectors o absorbents acústics, s'ha realitzat introduint tant la font sonora com el micròfon del sonòmetre a l'interior de la capsa (Figura 3).

Per finalitzar el treball experimental, s'han observat cadascun dels sis materials a través d'una lupa binocular a 40 augments, obtenint-ne de cadascun una fotografia que ens ha permès analitzar la seva estructura interna amb més detall. 


\section{Resultats obtinguts}

La taula 1 mostra els resultat obtinguts en les diferents mesures realitzades:

\begin{tabular}{|c|c|c|c|c|}
\hline \multirow[b]{2}{*}{$\begin{array}{l}\text { Capsa en } \\
\text { estudi }\end{array}$} & \multicolumn{2}{|c|}{$\begin{array}{c}\text { Sonòmetre a } \\
\text { l'exterior de la } \\
\text { capsa (aïllament) }\end{array}$} & \multicolumn{2}{|c|}{$\begin{array}{c}\text { Sonòmetre a } \\
\text { l'interior de la } \\
\text { capsa (reflexió i } \\
\text { absorció) } \\
\end{array}$} \\
\hline & $\begin{array}{c}\text { Intensitat } \\
\text { sonora a } \\
d=40 \mathrm{~cm} \\
(\mathrm{~dB})\end{array}$ & $\begin{array}{c}\Delta \mathrm{I} \\
(\%)\end{array}$ & 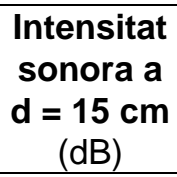 & $\begin{array}{c}\Delta \mathrm{I} \\
(\%)\end{array}$ \\
\hline $\begin{array}{c}\text { Font a } \\
\text { l'aire lliure } \\
\text { (sense } \\
\text { capsa) } \\
\end{array}$ & 80,0 & - & $86,7\left(^{*}\right)$ & - \\
\hline $\begin{array}{l}\text { Capsa de } \\
\text { llana de } \\
\text { roca }\end{array}$ & 68,1 & $\begin{array}{c}- \\
14,9 \\
\%\end{array}$ & 85,4 & $\begin{array}{c}- \\
1,5 \\
0 \%\end{array}$ \\
\hline $\begin{array}{l}\text { Capsa de } \\
\text { fusta } \\
\text { aglome- } \\
\text { rada }\end{array}$ & 69,0 & $\begin{array}{c}- \\
13,8 \\
\%\end{array}$ & 100,4 & $\begin{array}{c}+ \\
15 \\
8 \% \\
\end{array}$ \\
\hline $\begin{array}{c}\text { Capsa de } \\
\text { morter }\end{array}$ & 70,8 & $\begin{array}{c}- \\
11,5 \\
\%\end{array}$ & 104,4 & $\begin{array}{c}+ \\
20 \\
4 \% \\
\end{array}$ \\
\hline $\begin{array}{l}\text { Capsa de } \\
\text { porexpan }\end{array}$ & 74,5 & $\begin{array}{c}- \\
6,88 \\
\%\end{array}$ & 97,6 & $\begin{array}{c}+ \\
12 \\
6 \% \\
\end{array}$ \\
\hline $\begin{array}{c}\text { Capsa de } \\
\text { xapa } \\
\text { metàl-lica }\end{array}$ & 71,2 & $\begin{array}{c}- \\
11,0 \\
\%\end{array}$ & 99,0 & $\begin{array}{c}+ \\
14, \\
2 \% \\
\end{array}$ \\
\hline $\begin{array}{l}\text { Capsa de } \\
\text { rajola } \\
\text { esmaltada }\end{array}$ & 67,5 & $\begin{array}{c}- \\
15,6 \\
\%\end{array}$ & 103,2 & $\begin{array}{c}+ \\
19, \\
0 \%\end{array}$ \\
\hline
\end{tabular}

Taula 1. Decibels enregistrats pel sonòmetre.

$\left.{ }^{*}\right)$ Valor estimat

A través dels resultats de la taula 1 arribem a la conclusió que el material més aillant és la rajola esmaltada, disminuint la intensitat sonora en un $15,6 \%$. Aquest és el material que presenta més uniformitat en la seva estructura física: l'esmalt que cobreix una cara de la terrissa crea una capa llisa per la qual no passa l'aire, i, per tant, reflecteix la major part de l'energia cap al seu interior.

El material menys aïllant és el porexpan, ja que la intensitat sonora tant sols ha disminuït en un $6,88 \%$. És per això que aquest material no s'utilitza en construccions d'aïllament acústic (sí en canvi per a l'aïllament tèrmic). El fet que sigui tan poc aï- llant sonor és degut a que la seva estructura està formada per boletes ben juntes, però aquestes cel.les no estan intercomunicades i, per tant, el material no es comporta com un bon absorbent acústic. D'altra banda, no és un material gaire dens ni elàstic i això fa que tampoc reflecteixi gaire el so.

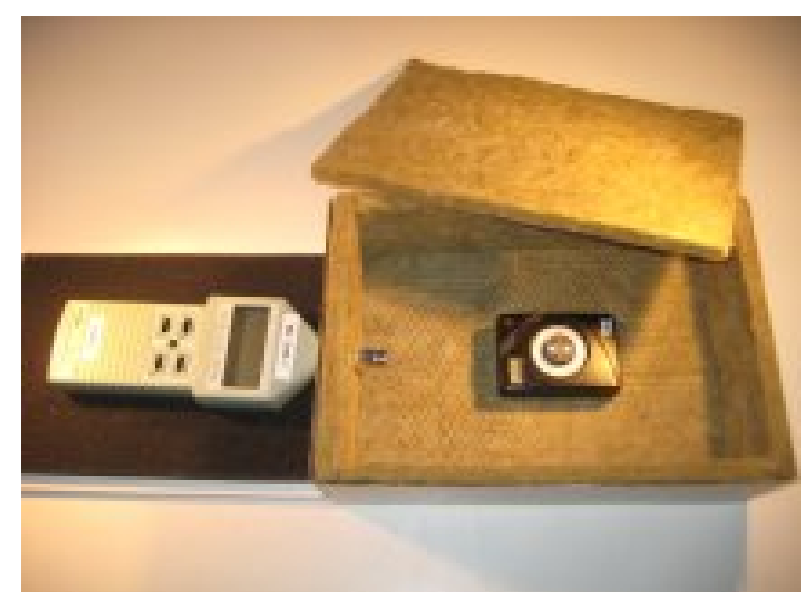

Figura 3. Font sonora i sonòmetre a l'interior de la capsa per tal de mesurar la capacitat reflectora o absorbent del material.

El material que més absorbeix ones sonores és la llana de roca, ja que el nivell d'intensitat sonora ha disminuït en un 1,50\%. Això implica que hi ha poques reflexions i que el so queda absorbit a les parets de la capsa. La llana de roca és un material compost per moltes fibres molt fines. Quan les ones sonores entren en contacte amb les fibres, es produeix una transformació de l'energia acústica en energia cinètica. El fet que sigui un material tan porós és la causa del seu elevat coeficient d'absorció (fig. 4).

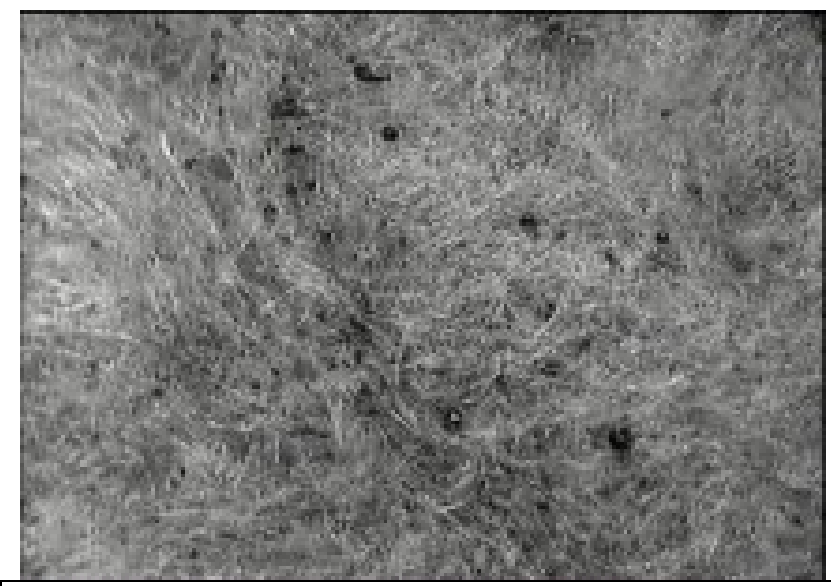

Figura 4. Mostra de llana de roca a 40 augments. 
El material més reflector dels sis estudiats és el morter (la intensitat sonora augmenta en un 20,4\% degut a les reflexions). El fet de que el ciment sigui un material d'estructura globular de microcel.les tancades i buides dificulta la transmissió de les ones sonores a través del material, de manera que una bona part de la seva energia es reflecteix dins la capsa.

\section{Valoració dels resultats i perspectives per a la docència}

El present treball ha permès a l'alumne relacionar les diverses disciplines científiques que fins ara i dins el currículum de l'ESO i el batxillerat ha estudiat de forma molt compartimentada.

Per una banda ha ampliat els coneixements de física i s'ha centrat en la branca de l'acústica i en el tema de la insonorització i del condicionament acústic en particular. D'altra banda ha portat a terme un acurat treball experimental en el que s'ha servit també -per a la construcció de les capsesde les eines que la tecnologia li proporciona.
A més el treball, emmarcat en una visió de ciència, tecnologia, societat (CTS), i utilitzant les tecnologies de la informació i la comunicació (TIC) ens ha permès també adquirir el material i els coneixements necessaris per tal de platejar-nos la possibilitat de dissenyar noves activitats pràctiques emmarcades en crèdits variables de l'àmbit científico-tècnic o bé en la matèria optativa de 4t d'ESO Física i Química.

\section{Agraïments}

Programa ARGÓ de la Universitat Autònoma de Barcelona (UAB).

\section{Bibliografia}

Expósito Pérez, Miquel (2009). L'acústica. Aïllament acústic $i$ condicionament d'un espai. Treball de recerca sense publicar. 